\title{
Model Following Control of a Higher Order Plant by a Lower Order Model
}

\author{
Rajesh Layek ${ }^{1}$, S. Mukherjee ${ }^{2}$ \\ ${ }^{1}$ Post Graduate Scholar, ${ }^{2}$ Professor, Department of Mechanical Engineering, Jalpaiguri Govt. \\ Engineering College, Jalpaiguri-735102, India. \\ 1rajeshlayek0320@gmail.com, ${ }^{2}$ sudipmukherjee_63@rediffmail.com.
}

\begin{abstract}
In this paper, based on Model Following Control (MFC) approach, a robust controller is used to control a flexible robot manipulator along a pre-defined trajectory. Here two degree of freedom plant is considered that has two different inertias. The plant is run by the single degree of freedom ideal model. Primarily, an ideal model is formulated from the mathematical expression and by selecting a suitable feedback amplifier gain a well-defined response is established. A reference input voltage is given to the model and the plant is driven by the errors, generated from the differences of the states between the plant and model. Here special attention is given to the fact that how precisely the states of the plant can follow the ideal states of the model. The proposed model following control (MFC) system may be used successfully in industrial robots.
\end{abstract}

Keywords: Robot manipulator, belt drive system, speed of response, overshoot, settling time, simulation, MFC system.

\section{INTRODUCTION}

In robotic applications, various kinds of feedback controllers are used. All feedback controllers are designed to eliminate the error between the process variable and the set point. Model following control (MFC) does so by forcing the process variable to reach the set point along a specified trajectory[1-3]. In industrial applications, the model following control approach has significantly increased the productivity with high accuracy and precision. Many researchers have been working on MFC for a long time [4], [5].

Here the MFC is implemented over two degree of freedom cylindrical robot manipulator. The manipulator, connected with the higher inertia is driven by the motor through a belt-drive arrangement. The desired trajectory is specified by creating a mathematical model that represents an idealized process [6].

This ideal process provides a more desirable response than the real or actual process. In case of actual process, various disturbances arise and it does not produce a very good response. Hence the plant is forced to follow the ideal states of the model [7], [8]. This is done by computing the errors between the states of the model and plant. These errors are multiplied by suitable error gains and are fed back to the system to get a satisfactory response from the plant [9].

\section{LITERATURE REVIEW}

Robot control systems were developed over a long time. A lot of research works have been done in the field since its inception. Some of the important works are mentioned below.

Mahmoud \&Bahnasawi (1992) have presented the simulation results on the first three joints of PUMA 560 robot manipulator through an adaptive model following control approach by using hyper stability theory. Trajectories, tracking errors, and required input torques of three joints were clearly defined in this research work. The satisfactory result is obtained from the proposed controller. The results of a simulation made on a 2 DOF plant (Robot Joint) driven by an ideal model were examined by Mukherjee et al. (1993). They have shown that satisfactory following of the model is possible under wide variations in the plant inertia. The performance robustness is remarkable and its implementation is not too much complex.

Jayawardene et al. (2003) have examined a belt drive robot arm positioned under acceleration and velocity constraints with restrained vibration through a modified taught data method.They achieved accurate positioning of the belt drive system under moderately higher velocity.

Dynamic modelling of glass substrate transfer robot arm through belt drive system was proposed by Kim et al. (2011). They used multiple belt drive systems. The experimental results of the proposed dynamic model could approximate the real dynamic system in terms of path errors. They have shown that the model is able to reduce the meandering of the path error.

The responses of a cylindrical robot manipulator which was undergoing some rotational movement were analysed 
by Ghosh \& Mukherjee(2018). They considered the shoulder joint of a cylindrical robot manipulator and the movement of the robot arm was simulated by using PID controller. The manipulator was controlled in such a way that it reached its desired position very fast without any overshoot and it settled down quickly.

\section{THE REFERENCE MODEL (IDEAL MODEL)}

Here the model is idealized in such a way that its response is ideal according to the control parameters. Here the shoulder joint of a cylindrical robot manipulator arm is considered. The physical parameters of the pulley are same as the larger inertia of the plant. The pulley is directly attached to a motor and it can be easily positioned [10], [11]. The schematic diagram of the ideal model is represented in figure 1.

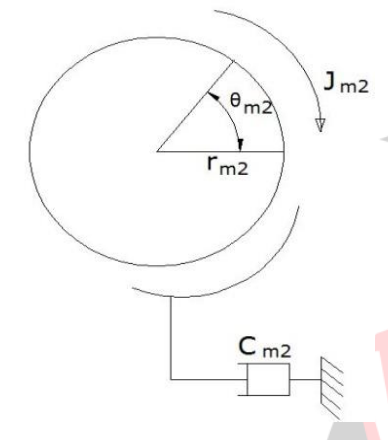

Figure 1. The ideal model

The equation of the ideal model is

$\mathrm{J}_{\mathrm{m} 2} \ddot{\theta}_{\mathrm{m} 2}+\mathrm{C}_{\mathrm{m} 2} \dot{\theta}_{\mathrm{m} 2}=\mathrm{T}_{\mathrm{m}}=\mu \mathrm{i}_{\mathrm{m}}$

Where, $\mathrm{i}_{\mathrm{m}}=\mathrm{A}\left(\mathrm{R}-\theta_{\mathrm{m} 2}\right)=\mathrm{Ae}$

After solving this equation, the ideal model is constructed by choosing a suitable amplifier feedback gain $\mathrm{A}$.

\section{THE ACTUAL SYSTEM (PLANT)}

The plant considered here has two inertias connected by a flexible belt. The larger inertia, shoulder joint of the robot arm is controlled by the rotation of the motor, which is connected with the smaller inertia [12]. Due to non-linear dynamic condition, vibration and belt flexibility, some errors arise between the states of the plant and model responses [13]. These errors are utilised to run the plant. The positional error and velocity error are as follows:

$\mathrm{e}_{2}=\left(\theta_{\mathrm{m} 2}-\theta_{\mathrm{p} 2}\right) ; \dot{\mathrm{e}}_{2}=\left(\dot{\theta}_{\mathrm{m} 2}-\dot{\theta}_{\mathrm{p} 2}\right)$

Suitable error gains are multiplied with these errors and they are fed back to operate the plant. Accordingly, the plant output is made to follow the ideal response of the model. The schematic diagram of the plant is shown in figure 2 [10].

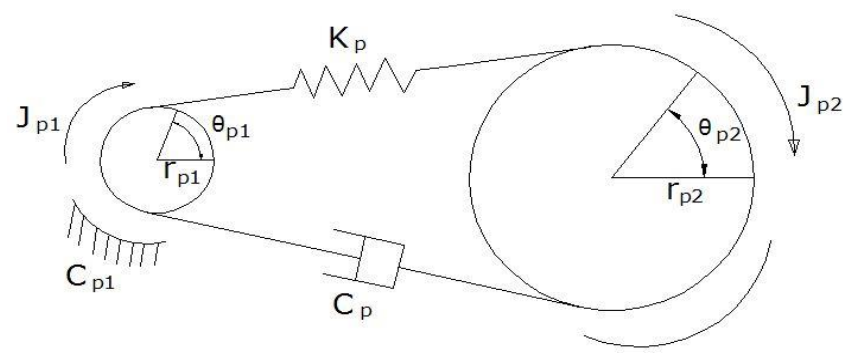

Figure2. The plant

The equations of the actual system are given by

$\mathrm{J}_{\mathrm{p} 1} \ddot{\theta}_{\mathrm{p} 1}+\mathrm{C}_{\mathrm{p} 1} \dot{\theta}_{\mathrm{p} 1}+\mathrm{C}_{\mathrm{p}} \mathrm{r}_{\mathrm{p} 1}\left(\mathrm{r}_{\mathrm{p} 1} \dot{\theta}_{\mathrm{p} 1}-\mathrm{r}_{\mathrm{p} 2} \dot{\theta}_{\mathrm{p} 2}\right)+\mathrm{K}_{\mathrm{p}} \mathrm{r}_{\mathrm{p} 1}\left(\mathrm{r}_{\mathrm{p} 1} \theta_{\mathrm{p} 1}-\mathrm{r}_{\mathrm{p} 2} \theta_{\mathrm{p} 2}\right)$ $=\mathrm{T}_{\mathrm{P}}=\mu \mathrm{i}_{\mathrm{p}}$

where, $i_{\mathrm{P}}=\mathrm{A}_{\mathrm{p} 2}\left(\theta_{\mathrm{m} 2}-\theta_{\mathrm{p} 2}\right)+\mathrm{A}_{\mathrm{d} 2}\left(\dot{\theta}_{\mathrm{m} 2}-\dot{\theta}_{\mathrm{p} 2}\right)=\mathrm{A}_{\mathrm{p} 2} \mathrm{e}_{2}+\mathrm{A}_{\mathrm{d} 2} \dot{\mathrm{e}}_{2}$

$\mathrm{J}_{\mathrm{p} 2} \ddot{\theta}_{\mathrm{p} 2}+\mathrm{C}_{\mathrm{p}} \mathrm{r}_{\mathrm{p} 2}\left(\mathrm{r}_{\mathrm{p} 2} \dot{\theta}_{\mathrm{p} 2}-\mathrm{r}_{\mathrm{p} 1} \dot{\theta}_{\mathrm{p} 1}\right)+\mathrm{K}_{\mathrm{p}} \mathrm{r}_{\mathrm{p} 2}\left(\mathrm{r}_{\mathrm{p} 2} \theta_{\mathrm{p} 2}-\mathrm{r}_{\mathrm{p} 1} \theta_{\mathrm{p} 1}\right)=0$ (3)

\section{THE MFC SCHEME}

Initially, the model following control system produces a well-defined trajectory of the ideal model, and then it influences the states of the plant to follow the pre-defined path. MFC adjusts the plant response in such a way that it can follow the states of the reference model [6]. Here an input is given to the reference model, but no input is given to the plant. The plant is run totally by the errors generated between the states of the reference model and the actual plant. $\mathrm{A}_{\mathrm{p} 2}$ and $\mathrm{A}_{\mathrm{d} 2}$ are suitable error gains selected to get the desired response from the plant [10]. The MFC scheme is shown in figure 3.

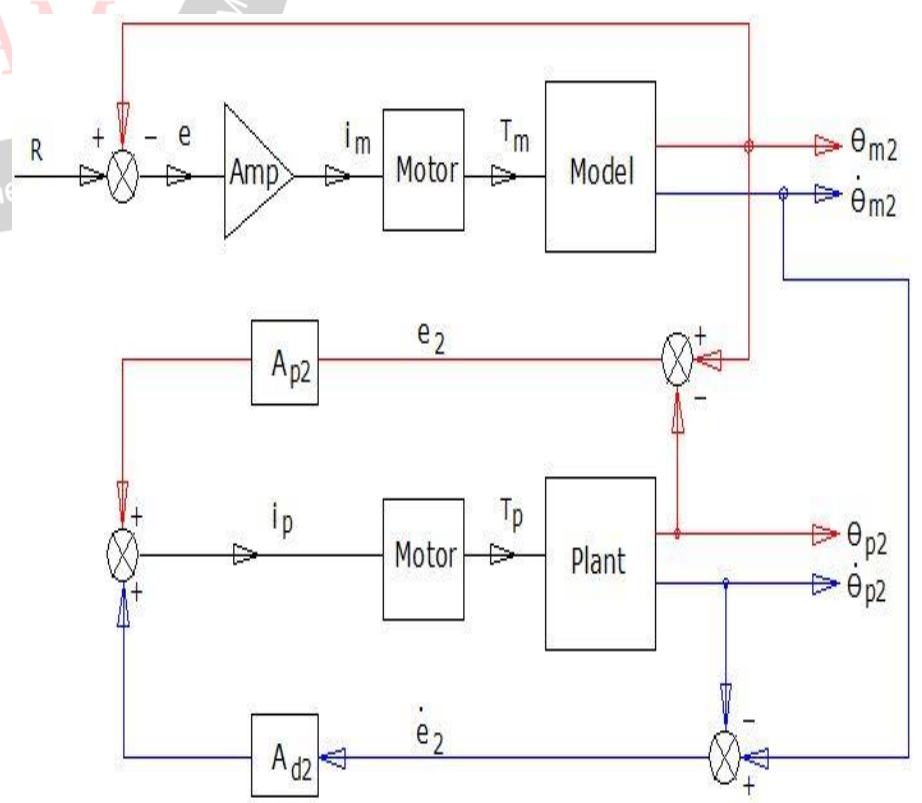

Figure 3. The model following control scheme 


\section{PARAMETERS OF THE PLANT AND MODEL}

Here an example is taken to check the effectiveness of the MFC scheme. Parameters of the plant and the model are given below.

$$
\begin{aligned}
& \mathrm{J}_{\mathrm{m} 2} \quad=\text { moment of Inertia of pulley (model) } \\
& =0.071 \mathrm{~kg} \mathrm{~m}^{2} \text {; } \\
& \mathrm{r}_{\mathrm{m} 2} \quad=\text { radius of pulley }(\text { model })=0.0382 \mathrm{~m} \text {; } \\
& \theta_{\mathrm{m} 2} \quad=\text { system co-ordinate (model), rad; } \\
& \dot{\theta}_{\mathrm{m} 2} \quad=\text { velocity co-ordinate (model), rad; } \\
& \mathrm{C}_{\mathrm{m} 2}=\text { damping coefficient of the pulley (model) } \\
& =5.5 \mathrm{~N}-\mathrm{m}-\mathrm{s} / \mathrm{rad} \text {; } \\
& \mathrm{T}_{\mathrm{m}} \quad=\text { input torque (model); } \\
& \mathrm{i}_{\mathrm{m}} \quad=\text { armature current (model); } \\
& \mu \quad=\text { motor torque constant }=1.25 \mathrm{~N} \mathrm{~m} / \mathrm{A} \text {; } \\
& \mathrm{R} \quad=\text { step input }(\text { model })=1 \text {; } \\
& \mathrm{A} \quad=\text { feedback amplifier gain }(\text { model })=100 \text {; } \\
& \text { e } \quad=\left(\mathrm{R}-\theta_{\mathrm{m} 2}\right)=\text { feedback error (model); } \\
& \mathrm{J}_{\mathrm{p} 1}, \mathrm{~J}_{\mathrm{p} 2}=\text { moment of Inertia of smaller and bigger pulleys } \\
& \text { (plant) }=0.0018 \mathrm{kgm}^{2} \& 0.071 \mathrm{kgm}^{2} \text { respectively; } \\
& \mathrm{r}_{\mathrm{p} 1}, \mathrm{r}_{\mathrm{p} 2}=\text { radii of smaller and bigger pulleys (plant) } \\
& =0.00955 \mathrm{~m} \& 0.0382 \mathrm{~m} \text { respectively; } \\
& \theta_{\mathrm{p} 1}, \theta_{\mathrm{p} 2}=\text { system co-ordinates (plant), rad; } \\
& \dot{\theta}_{\mathrm{p} 1}, \dot{\theta}_{\mathrm{p} 2}=\text { velocity co-ordinates (plant), rad; } \\
& \mathrm{K}_{\mathrm{p}} \quad=\text { belt stiffness (plant) }=5 \times 10^{5} \mathrm{~N} / \mathrm{m} \text {; } \\
& \mathrm{C}_{\mathrm{p}} \quad=\text { damping constant of the belt (plant) } \\
& =2500 \mathrm{Ns} / \mathrm{m} \text {; } \\
& \mathrm{C}_{\mathrm{p} 1} \quad=\text { damping coefficient }(\text { plant })=0.05 \mathrm{~N}-\mathrm{m}-\mathrm{s} / \mathrm{rad} \text {; } \\
& \mathrm{T}_{\mathrm{p}} \quad=\text { input torque (plant); } \\
& \mathrm{i}_{\mathrm{p}} \quad=\text { armature current (plant); } \\
& \mathrm{A}_{\mathrm{p} 2} \quad=\text { position error feedback gain (plant); } \\
& \mathrm{A}_{\mathrm{d} 2}=\text { velocity error feedback gain (plant); } \\
& \mathrm{e}_{2}=\left(\theta_{\mathrm{m} 2}-\theta_{\mathrm{p} 2}\right)=\text { position error of bigger pulley; } \\
& \dot{\mathrm{e}}_{2}=\left(\dot{\theta}_{\mathrm{m} 2}-\dot{\theta}_{\mathrm{p} 2}\right)=\text { velocity error of bigger pulley; }
\end{aligned}
$$

\section{SIMULATION RESULTS}

The simulation results are found through computer programming by solving equations (1), (2) \& (3). During the simulation, it is observed that the response of the model is very fast with a speed of response is about 0.14 sec. It has no overshoot and no steady state error with respect to the reference input. Here in the reference model, a proper feedback amplifier gain (100) is selected to get the best response. The ideal response is shown in figure 4 .

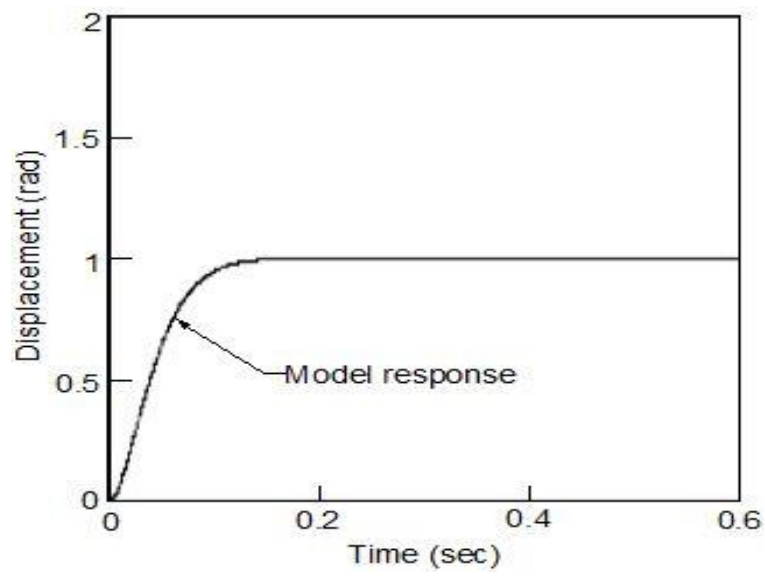

Figure 4. Response of the model

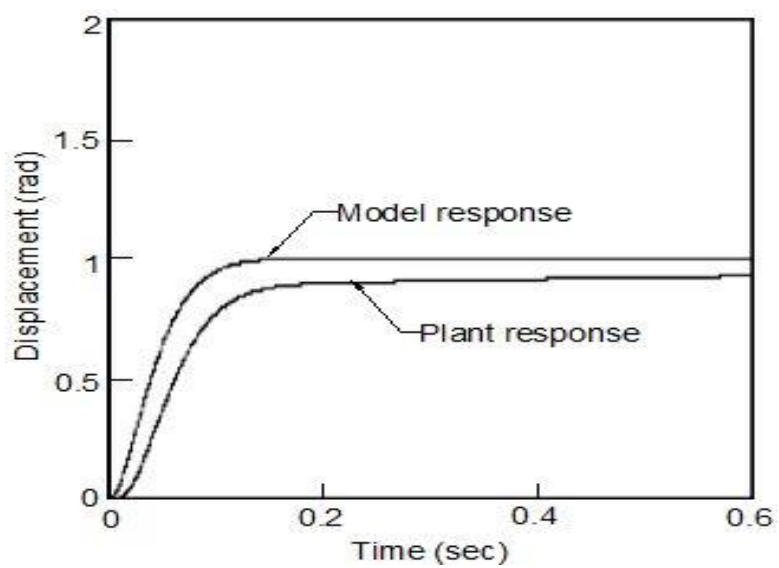

Figure 5. Model and plant responses $\left(A_{\mathrm{p} 2}=1, \mathrm{~A}_{\mathrm{d} 2}=1\right)$

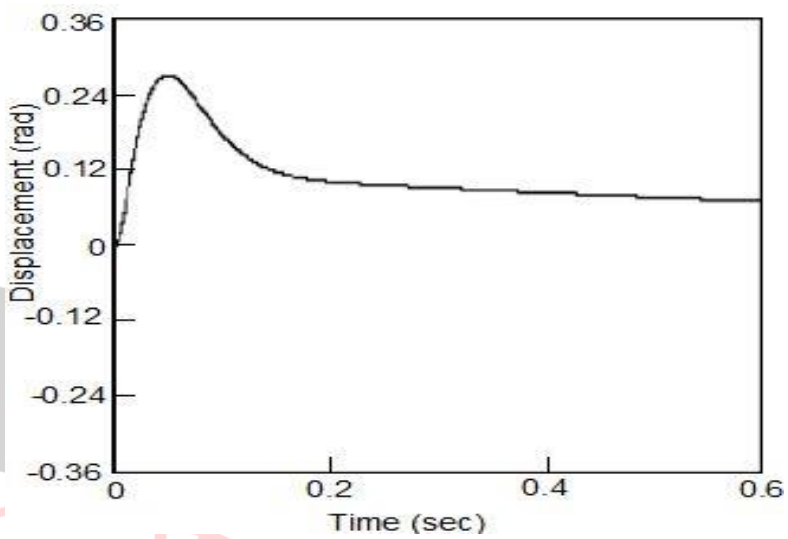

Figure 6. Position error $\left(A_{p 2}=1, A_{d 2}=1\right)$

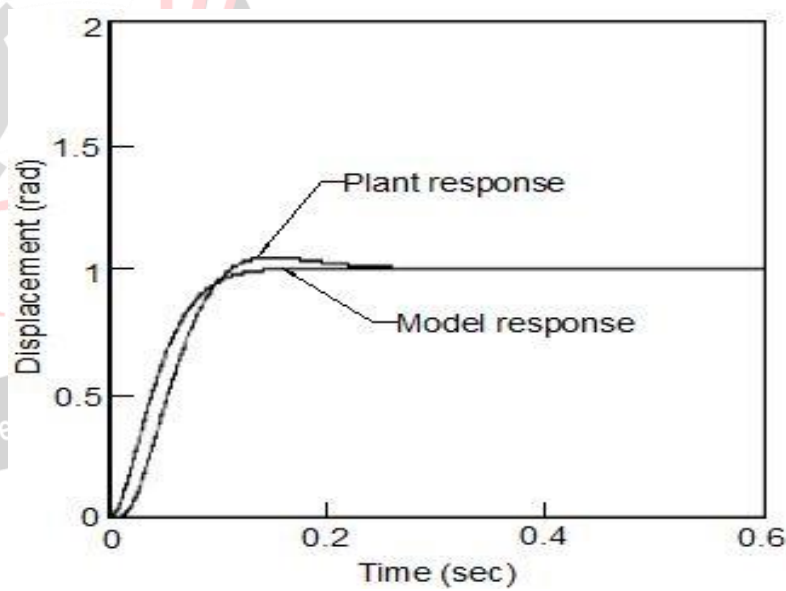

Figure 7. Model and plant responses $\left(A_{p 2}=20, A_{d 2}=1\right)$

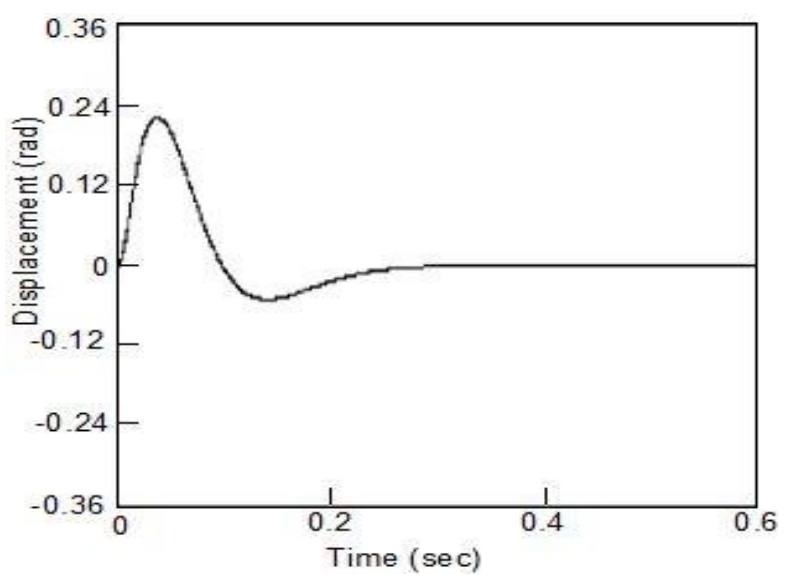

Figure 8. Position error $\left(A_{\mathrm{p} 2}=20, \mathrm{~A}_{\mathrm{d} 2}=1\right)$ 


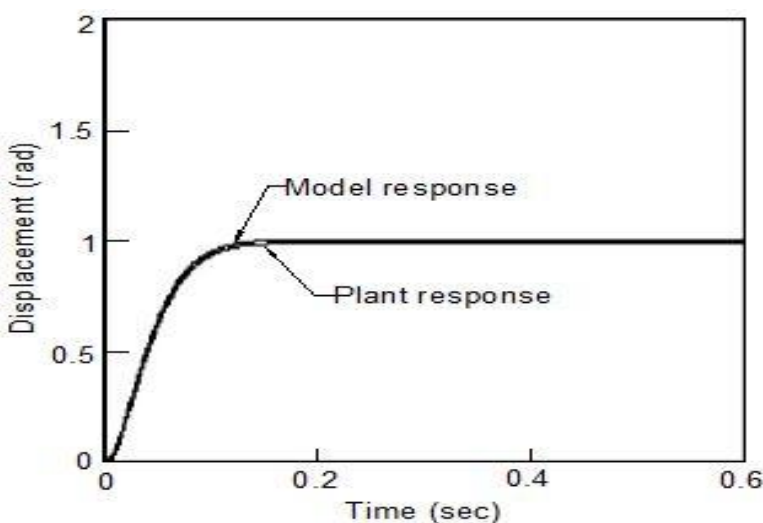

Figure 9. Model and plant responses $\left(\mathrm{A}_{\mathrm{p} 2}=1, \mathrm{~A}_{\mathrm{d} 2}=20\right)$

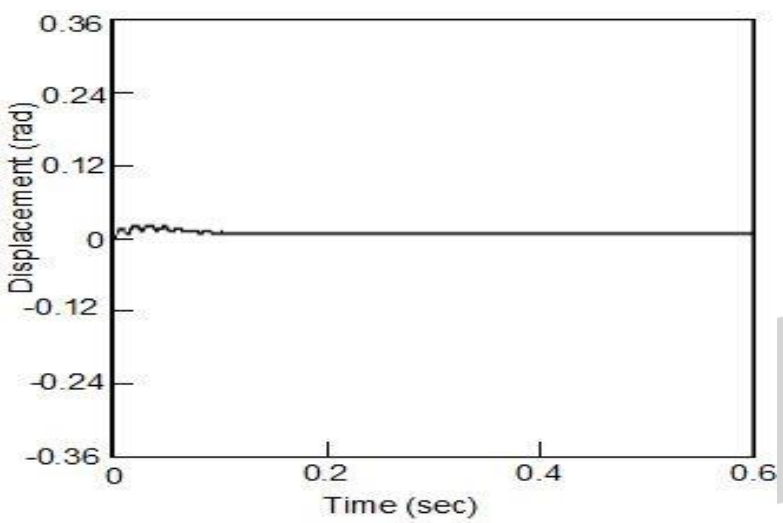

Figure 10. Position error $\left(A_{p 2}=1, A_{d 2}=20\right)$

The system responses are simulated for various error gains. Figures 5 to 12 show some of the responses and position errors between the plant and model. Here it is shown that how the response of the system is improved by reducing the position error.

Figure 5 indicates the responses of the model and plant for gains $A_{p 2}=1, A_{d 2}=1$. Here the speed of response of the plant is very slow and it reaches its target point after a comparatively long time (around $2 \mathrm{sec}$ ). From figure 6 , it is seen that initially the position error of the plant increases, and the maximum error is $0.27 \mathrm{rad}$. Then it converges to zero after a long time, which is about more than $2 \mathrm{sec}$. That's why the response of the plant is very slow for these gain values.

It can be seen in figure 7, that the speed of response is very fast (around $0.1 \mathrm{sec}$ ) for gains $\mathrm{A}_{\mathrm{p} 2}=20, \mathrm{~A}_{\mathrm{d} 2}=1$, but overshoot increases when position error gain increases. It has a large position error and it converges to zero after $0.27 \mathrm{sec}$ which is shown in figure 8 . So position error gain

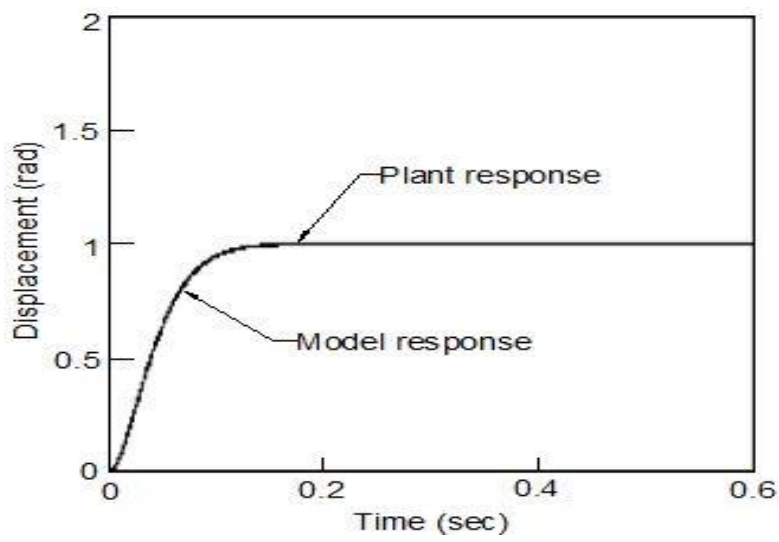

Figure 11. Model and plant responses $\left(A_{p 2}=1, A_{d 2}=35\right)$

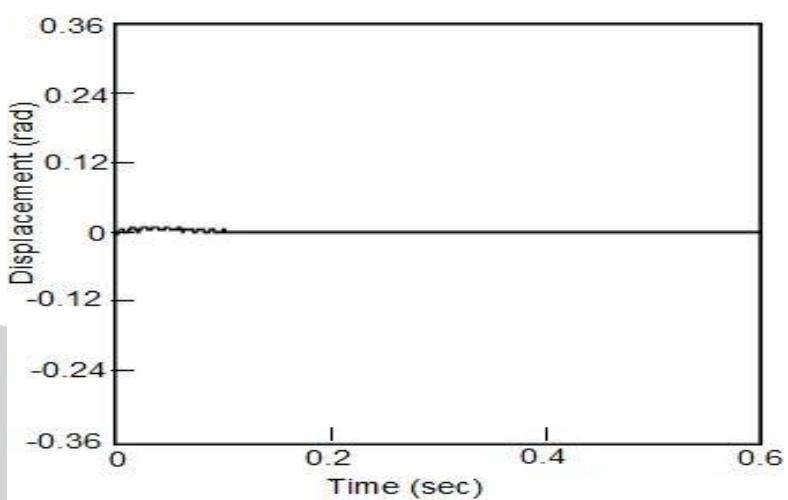

Figure 12. Position error $\left(A_{p 2}=1, A_{d 2}=35\right)$

should be kept at some lower value which is taken to be $\mathrm{A}_{\mathrm{p} 2}=1$.

Figure 9 shows the responses of the plant and model for gains $A_{p 2}=1, A_{d 2}=20$. Very small error arises at the beginning for a lesser period of time and then it is gradually reduced, which is shown in figure 10 . Here the response of the plant is almost identical to the response of the model, but a slight steady-state error is present.

Figure 11 provides the best following of the plant response towards the model response which is achieved by adjusting the error gains at $\mathrm{A}_{\mathrm{p} 2}=1$ and $\mathrm{A}_{\mathrm{d} 2}=35$. The position error is very minimal. Figure 12 shows the position error for the best combination of gains. At the beginning of time very minor oscillations occur, and the oscillations subside within $0.14 \mathrm{sec}$. Hence, the plant can easily track the model. It is clearly visible that the model and plant responses cannot be identified separately.

The states of the reference model and plant are tabulated in Tables-1, 2.

\section{Table-1. Output of the reference model}

\begin{tabular}{|c|c|c|c|c|c|c|}
\hline $\begin{array}{c}\text { Sl. } \\
\text { no. }\end{array}$ & $\begin{array}{c}\text { Fig. } \\
\text { no. }\end{array}$ & $\begin{array}{c}\text { Gain } \\
(\mathrm{A})\end{array}$ & $\begin{array}{c}\text { Speed of response } \\
(\mathrm{T}) \text { Sec. }\end{array}$ & $\begin{array}{c}\text { Overshoot } \\
\text { (rad.) }\end{array}$ & $\begin{array}{c}\text { Settling time } \\
(\mathrm{T}) \text { Sec. }\end{array}$ & $\begin{array}{c}\text { Steady state error } \\
\text { (rad.) }\end{array}$ \\
\hline $\mathbf{1}$ & $\mathbf{4}$ & $\mathbf{1 0 0}$ & $\mathbf{0 . 1 4}$ & $\mathbf{0}$ & $\mathbf{0 . 1 4}$ & $\mathbf{0}$ \\
\hline
\end{tabular}

Table-2. Output of the actual system

\begin{tabular}{|c|c|c|c|c|c|c|c|}
\hline \multirow{2}{*}{$\begin{array}{l}\text { S1. } \\
\text { no. }\end{array}$} & \multirow{2}{*}{$\begin{array}{l}\text { Fig. } \\
\text { no. }\end{array}$} & \multicolumn{2}{|c|}{ Gain } & \multirow{2}{*}{$\begin{array}{l}\text { Speed of } \\
\text { response } \\
\text { (T) Sec. }\end{array}$} & \multirow{2}{*}{$\begin{array}{l}\text { Overshoot } \\
\text { (rad.) }\end{array}$} & \multirow{2}{*}{$\begin{array}{l}\text { Settling time } \\
\text { (T) Sec. }\end{array}$} & \multirow{2}{*}{$\begin{array}{l}\text { Steady state error } \\
\text { (rad.) }\end{array}$} \\
\hline & & $A_{p 2}$ & $\mathrm{~A}_{\mathrm{d} 2}$ & & & & \\
\hline 1 & 5 & 1 & 1 & 2 & 0 & 2 & -0.005096 \\
\hline 2 & 7 & 20 & 1 & 0.10 & 0.0452 & 0.27 & 0.000019 \\
\hline 3 & 9 & 1 & 20 & 0.17 & 0 & 0.17 & -0.007500 \\
\hline 4 & 11 & 1 & 35 & 0.14 & 0 & 0.14 & 0 \\
\hline
\end{tabular}




\section{CONCLUSIONS}

The model following control scheme has been applied to control the motion of the robot manipulator. The simulation results of the plant are developed and shown in this paper. Here the notable thing is that a single degree of freedom model is able to force the two degree of freedom plant to follow its ideal response successfully and accurately. Initially the ideal model is created and an input is given to the model and no extra input is given to the plant. The errors between the states of the reference model and plant are utilised to run the plant. Here the control is simplified to proper adjustment of the error gains to produce a satisfactory response from the plant. The results demonstrate an outstanding performance of the proposed MFC control scheme. It can be implemented quite easily in modern robotic requirements.

\section{REFERENCES}

[1] Hiroki Shibasaki, RubiyahYusof and Yoshihisa Ishida, "A Design Method of a Model-following Control System", International Journal of Control, Automation, and Systems, (2015) 13(4):1-10 DOI 10.1007/s12555-014-0131-3.

[2] Stanislaw Skoczowski, “ Robust model following control with use of a plant model”, International Journal of Systems Science, 2001, volume 32, number 12, pages 1413-1427.

[3] Magdi S. Mahmoud \&Ahmed A. Bahnasawi, "A Design Approach to Adaptive Model-Following Control of Robotic Manipulators", Journal of Intelligent and Robotic Systems, 10: 191-207, 1994.

[4] Raham H. Mohammed, Fahmy Bendary, Kamel Elserafy, "Trajectory Tracking Control for Robot Manipulator using Fractional Order- Fuzzy-PID Controller", International Journal of Computer Applications, volume-135 - no. 15, january 2016.

[5] Byung Kook Kim, Kang G. Shin, "An Adaptive Model Following Control of Industrial Manipulators", IEEE Transactions on Aerospace and Electronic Systems, AES-19(6):805-814, December1983 DOI:10.1109/TAES.1983.309392.

[6] S. Mukherjee, S. Mukhopadhyay, S. N. Sengupta, "Model Following Control of a Variable Inertia Positioner", The International Journal of Robotics Research, Vol -12, Issue -5,1993, DOI:10.1177/027836499301200509.

[7] Ryoichiro Haruyama, Shota Inoue \& Yoshihisa .Ishida, "Design of a Model-Following Servo Controller for Multiple- input-multiple- output
Systems with Improved Robustnes", 2016 IEEE 12th International Colloquium on Signal processing \& its Application,(CSPA2016), 4 - 6 March 2016, Melaka, Malaysia.

[8] Tae-Hyun Kim, Min-Su Jegal, Joonyoung Kim, Jae-Hwan Choe, and Sung-Rak Kim, "Dynamic Modeling of Flexible Glass Substrate Transfer Robot Arm and Meandering Estimation", Conference: IEEE International Conference on Robotics and Automation, ICRA 2011, Shanghai, China, 9-13 May 2011 DOI:10.1109/ICRA.2011.5980594.

[9] Inoue S. \& Ishida Y, "Design of a Modelfollowing Controller Using a Decoupling Active Disturbance Rejection Control Method",Journal of Electrical \& Electronic Systems.5: 174, 2016 DOI:10.4172/2332-0796.1000174.

[10] S. Mukherjee \& S. N. Sengupta, "Control of a robotic manipulator-a model following approach", Indian Journal of Engineering \&Material Sciences, Voume-1, pp 70-76, April,1994.

[11] Emmanuel C. Agbaraji1, Hyacinth C. Inyiama and Christiana C. Okezie, "Dynamic Modeling of a 3DOF Articulated Robotic Manipulator Based on Independent Joint Scheme", Physical Science International Journal, 15(1): 1-10, 2017; Article no.PSIJ.33578, DOI: 10.9734/PSIJ/2017/33578.

[12] Sudipta Ghosh, S.Mukherjee, "PID Control of a Single Degree of Freedom Flexible Robot Manipulator", International Journal ofResearch in Engineering Application \& Management(ijream). Vol-04, Issue-03, June,2018,DOI : 10.18231/24549150.2018 .0315 .

[13] Johnson, H. M., \& Pszczel, M. B. "Model Reference Adaptive Control and Identification for Nonlinear Systems: Methods and Applications Adaptive Systems in Control and Signal Processing", IFAC Proceedings, Volume 25, Issue 14, July 1992, Pages 107-112, DOI:10.1016/s1474-6670(17)50720-x, 1992. 